
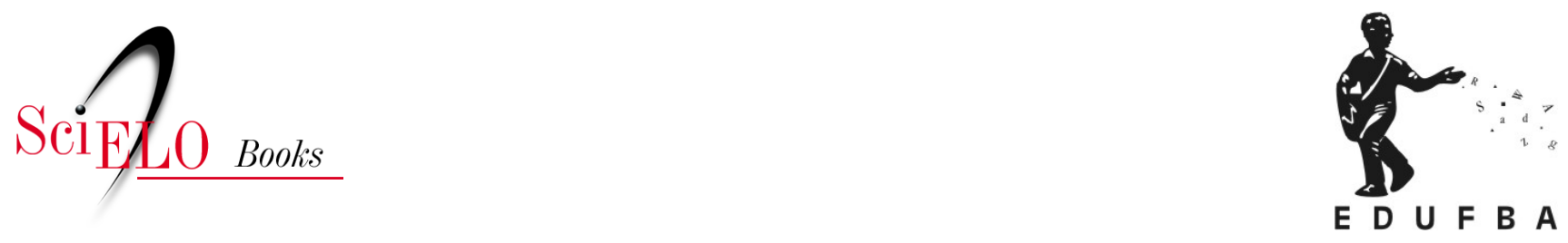

\title{
3 Tribo Mutisieae Cass.
}

\author{
Eduardo Pasini
}

PAINI, E. Tribo Mutisieae Cass. In: ROQUE, N. TELES, A.M., and NAKAJIMA, J.N., comp. A família Asteraceae no Brasil: classificação e diversidade [online]. Salvador: EDUFBA, 2017, pp. 43-50. ISBN: 978-85-232-1999-4. https://doi.org/10.7476/9788523219994.0005.

All the contents of this work, except where otherwise noted, is licensed under a Creative Commons Attribution 4.0 $\underline{\text { International license. }}$

Todo o conteúdo deste trabalho, exceto quando houver ressalva, é publicado sob a licença Creative Commons Atribição $\underline{4.0}$. 


\section{TRIBO MUTISIEAE CASS.}

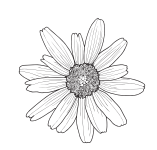

Eduardo Pasini

A compreensão da tribo Mutisieae s.l. é essencial para elucidar a radiação evolutiva e as relações de parentesco entre as Asteraceae basais (FUNK et al., 2009), além de proporcionar o entendimento de gêneros muito peculiares e isolados (BREMER, 1994).

Cabrera (1977) realizou o estudo mais completo e global envolvendo a tribo Mutisieae, cuja classificação serviu de subsídio até a descoberta da subtribo Barnadesiinae Benth. \& Hook como grupo irmão para o resto da família (JANSEN; PALMER, 1987).

Estudos revisivos e cladísticos, como de Cabrera (1977), Hansen (1991), Karis, Kallersjoån e Bremer (1992), Bremer e Jansen 1992 e Bremer (1994, 1996), invariavelmente, concluíram que a tribo Mutisieae (sensu Cabrera) era parafilética e necessitava ser desmembrada. Contudo, esses estudos não apresentaram um consenso para a obtenção de uma classificação estável para o grupo, de modo que conclusões sobre a sua circunscrição eram ainda contraditórias.

Recentemente, análises com base em filogenias moleculares, tais como as de Panero e Funk (2002, 2007, 2008) e Funk e colaboradores (2009), propuseram a divisão das Mutisieae em 13 tribos. Algumas dessas tribos são morfologicamente distintas e reconhecidas como clados (Barnadesieae, Nassauvieae, Onoserideae, Mutisieae, Gochnatieae, Hecastocleideae, Tarchonantheae, Oldenburgieae, Dicomeae e Pertyeae), enquanto outras (Stifftieae, Hyalideae, Wunderlichieae) e suas subfamílias (Stifftioideae, Wunderlichioideae) não são uniformemente aceitas (FUNK et al., 2014; KATINAS et al., 2008, ORTIZ et al., 2009). 
Segundo a classificação proposta por Funk e colaboradores (2009), Mutisieae s. str. compreende 14 gêneros e aproximadamente 200 espécies, com distribuição predominante na América do Sul, mas com representantes na América do Norte, América Central, Ásia, África e Austrália. A tribo pode ser reconhecida pelos hábitos herbáceos, arbustivos ou trepadeiras, com grande variação na corola (bilabiada, sub-bilabiada, tubular, filiforme, ligulada) e, algumas vezes, as corolas marginais são conspicuamente expandidas e muito vistosas (vermelhas, amarelas, amarelo-alaranjadas, alaranjadas, brancas ou lilás). As anteras apresentam apêndices basais caudados, estilete bilobado a bífido, com ápices dos ramos arredondados e papilosos acima do ponto de bifurcação. As cipselas são comumente truncadas ou rostradas no ápice, apresentam papilas arredondadas e pápus geralmente unisseriado e isomorfo (BREMER, 1994; KATINAS et al., 2009).

\section{Descrição}

Arbustos, subarbustos, ervas eretas ou rasteiras, trepadeiras herbáceas ou lenhosas, anuais ou perenes, monoicos, dioicos ou ginodioicos. Folhas alternas, raramente opostas ou rosuladas, esparsas ou densamente imbricadas, dispostas ou não em braquiblastos ou macroblastos (por exemplo, Brachyclados) ou apresentar gavinhas terminais (por exemplo, Mutisia), pecioladas, sésseis ou subsésseis; lâminas simples ou compostas, pinatissectas ou pinadas, liradas, deltoides, elípticas, espatuladas, lanceoladas, lineares, ovadas, obovadas, subuladas, coriáceas, cartáceas ou papiráceas, venação pinada, palmada a 3-nervada, raramente paralelinérvia, glabras, pubescentes, tomentosas ou lanosas. Capitulescência corimbiforme, racemiforme, paniculiforme, glomeruliforme ou capítulo solitário, invólucro campanulado, cilíndrico ou hemisférico; receptáculo epaleáceo, setoso, fimbriado, piloso ou glabro. Capítulos pedunculados ou sésseis, homógamos ou heterógamos, discoides, disciformes ou radiados, isomórficos ou heteromórficos com flores dimórficas, subdimórficas ou trimórficas (por exemplo, Chaptalia); brácteas involucrais unisseriadas ou multisseriadas, imbricadas. Flores casmógamas ou cleistógamas, amarelas, amarelo-alaranjadas, alaranjadas, brancas, lilás ou vermelhas, tubo da corola glabro, pubescente ou com tricomas 
glandulares. Capítulos, quando isomórficos, com todas as flores bissexuais ou rara e funcionalmente pistiladas, corolas liguladas, sub-bilabiadas a tubular-filiformes. Capítulos, quando heteromórficos, com flores marginais bissexuais, pistiladas ou neutras, corolas bilabiadas (Figura 1J), sub-bilabiadas ou do raio verdadeiras, com ou sem estaminódios; flores intermediárias (capítulos trimórficos) pistiladas, corolas filiformes a bilabiadas, com ou sem estaminódios; flores centrais bissexuais, funcionalmente pistiladas ou estaminadas, corolas bilabiadas, sub-bilabiadas, tubular-bilabiadas, tubularfiliformes a subcampanuladas; estames com apêndices apicais das anteras lanceolados, arredondados, agudos, apêndices basais das anteras caudados ou sagitados, raramente curtos, lisos a papilosos; estilete bilobado, ramos dorsalmente glabros a papilosos, papilas distribuídas acima do ponto de bifurcação, papilas curtas e arredondadas no ápice. Cipselas cilíndricas ou oblongas a obovadas, rostradas, atenuadas ou truncadas no ápice, glabras a pubescentes; pápus com cerdas escabrosas a plumosas, conadas ou não na base (por exemplo, Perdicium) ou ausente (por exemplo, Adenocaulon).

No Brasil, a tribo está representada pelos gêneros Chaptalia (17 spp.) (Figuras 2E-G), Lulia (1 sp.), Mutisia (4 spp.) (Figura 2H) e Trichocline (8 spp.) (Figuras 2I e 3A). Dentre as espécies de Chaptalia, oito são endêmicas do país, ocorrendo predominantemente no Sul do Brasil. Lulia, gênero monoespecífico, ocorre nos campos de altitude do domínio mata atlântica no Sudeste do Brasil, em banhados com turfeiras. Mutisia, com distribuição no Sudeste e Sul do país e em vegetação de Mata Atlântica, apresenta apenas uma espécie endêmica, Mutisia lutzii G.M. Barroso, encontrada na Serra do Caparaó, no estado de Minas Gerais. Trichocline apresenta duas espécies endêmicas do Sul do Brasil, T. catharinensis Cabrera e T. linearifolia Malme, a primeira ocorrendo amplamente em todo o Sul do país e a segunda restrita aos campos de altitude da Serra do Mar, nos estados do Paraná e São Paulo.

\section{Chave de identificação para os gêneros de Mutisieae no Brasil}

1. Ervas eretas; folhas alternas com nervação paralelinérvia ................ Lulia 1'. Ervas em roseta (Figuras 2G, I) ou trepadeiras; folhas com nervação pinada. 
2. Trepadeiras; folhas compostas, pinadas, com gavinhas terminais; cipselas cilíndricas, pápus formado por cerdas plumosas (Figura 1I)............... Mutisia 2'. Ervas em roseta; folhas simples, liradas ou lobadas a pinatissectas; cipselas oblongas a obovadas, pápus formado por cerdas escabrosas .......... 3

3. Sistema radicular extenso, formado por xilopódio; cipselas truncadas no ápice com tricomas claviformes, curtos e adensados (Figura 1K)

Trichocline

3'. Rizoma, quando presente, de dimensões pequenas; cipsela rostrada a atenuada no ápice, com tricomas alongados e esparsos ou ausentes 4

4. Capítulos com flores dimórficas ou trimórficas quando trimórficas, as intermediárias com corola bilabiada a filiforme-bilabiada, mais longa que o estilete ou do mesmo tamanho, estaminódios presentes, pápus plurisseriado Gerbera

4'. Capítulos com flores dimórficas ou trimórficas; quando trimórficas, as intermediárias com corola reduzida, filiforme, mais curta que o estilete, estaminódios ausentes, pápus unisseriado Chaptalia

\section{Literatura recomendada}

BREMER, K. Asteraceae: cladistics and classification. Portland: Timber Press, 1994.

BREMER, K.; JANSEN, R.K. A new subfamily of the Asteraceae. Annals of Missouri Botanical Gardens, Saint Louis, v. 79, p. 414-415, 1992.

Bremer, K., 1996. Major clades and grades of the Asteraceae. In: HIND, D. J. N.; BEENTJE, H. J. (Ed.). Compositae: Proceedings of the International Asteraceae Conference 1994. Kew: Royal Botanic Gardens, 1996. v. 1. p. 1-7.

BURKART, A. Estudio del género de Compuestas Chaptalia con especial referencia a las especies argentinas. Darwiniana, Buenos Aires, t. 6, n. 4, p. 505-594, 1944. 
CABRERA, A. L. Revisión del género Mutisia (Compositae). Opera Lilloana, Tucuman, v. 13, p. 5-227, 1965.

CABRERA, A. L.; KLEIN, R. M. Compostas. Tribo: Mutisieae. Flora Ilustrada Catarinense. Itajaí: Herbário Barbosa Rodrigues, 1973.

CABRERA, A. L. Mutisieae: systematic review. In: HEYWOOD, V. H.; HARBORNE, J. B.; TURNER, B. L. (Ed.). The Biology and Chemistry of the Compositae. London: Academic Press, 1977. v. 2. p. 1039-1066.

FUNK, V. A. et al. (Ed.). Systematics, Evolution and Biogeography of Compositae. Vienna: IAPT, 2009.

FUNK, V. A. et al. A phylogeny of the Gochnatieae: understanding a critically placed tribe in the Compositae. Taxon, Utrecht, v. 63, n. 4, p. 859-88, 2014.

HANSEN, H. V. Phylogenetic studies in the Gerbera complex (Compositae, tribe Mutisieae, subtribe Mutisinae). Nordic Journal of Botany, Copenhagen, v. 9, n. 5, p. 469-485, 1990.

HANSEN, H. V. Phylogenetic studies in Compositae tribe Mutisieae. Opera Botanica, Lund, v. 109, p. 1-50, 1991.

HIND, D. J. N. Tribe Mutisieae. In: KADEREIT, J. W.; JEFFREY, C. (Ed.). The Families and Genera of Vascular Plant: v. VIII: Flowering Plants Eudicots: Asterales. Berlin: Springer, 2007. p. 90-123.

JANSEN, R. K., PALMER, J. D., A chloroplast DNA inversion marks an ancient evolutionary split in the sunflower family (Asteraceae). Proceedings of the National Academy of Sciences of the United States of America, Washington, v. 84, n. 16 , p. 5818-5822, 1987.

KARIS, P. O., KALLERSJOÅN, M.; BREMER, K. Phylogenetic analysis of the Cichorioideae (Asteraceae) with emphasis on the Mutisieae. Annals of Missouri Botanical Garden, v. 79, p. 416-427, 1992.

KATINAS, L. The Gerbera-complex (Asteraceae, Mutisieae): to split or not to split. Sida, [S.1.], v. 21, p. 935-940, 2004.

KATINAS, L. et al. The subfamily Mutisioideae (Asteraceae). The Botanical Review, Bronx, n. 74, p. 469-716, 2008. 
KATINAS, L. et al. Mutisieae sensu stricto (Mutisioideae sensu strito). In: FUNK, V. A. et al. (Ed.). Systematics, Evolution, and Biogeography of Compositae. Vienna, Austria: International Association for Plant Taxonomy, 2009. p. 229-248.

MONDIN, C. A. A tribo Mutisieae Cass. (Asteraceae), sensu Cabrera, no Rio Grande do Sul e suas relações biogeográficas. 1996. 161 f. Dissertação (Mestrado em Botânica) - Instituto de Biociências, Universidade Federal do Rio Grande do Sul, Porto Alegre, 1996.

ORTIZ, S. et al. The basal grade of Compositae: Mutisieae (sensu Cabrera) and Carduoideae. In: FUNK, V. A. et al. (Ed.). Systematics, Evolution, and Biogeography of Compositae. Vienna, Austria: International Association for Plant Taxonomy, 2009. p. 193-213.

PANERO, J. L.; FUNK, V. A. New infrafamilial taxa in Asteraceae. Phytologia, Huntsville, v. 89, n. 3, p. 356-360, 2007.

PANERO, J. L.; FUNK, V. A. Toward a phylogenetic subfamilial classification for the Compositae (Asteraceae). Proceedings of the Biological Society of Washington, Washington, v. 115, n. 4, p. 909-922, 2002.

PANERO, J. L.; FUNK, V. A. The value of sampling anomalous taxa in phylogenetic studies: major clades of the Compositae revealed. Molecular Phylogenetics and Evolution, Orlando, v. 47, n. 2, p. 757-782, 2008.

ZARDINI, E. M. Lulia: un nuevo género de Compuestas. Boletín de la Sociedad Argentina de Botánica, Córdoba, v. 19, p. 255-258, 1980.

ZARDINI, E. M. Revision del género Trichocline (Compositae). Darwiniana, Buenos Aires, t. 19, n. 2/4, p. 618-733, 1975. 


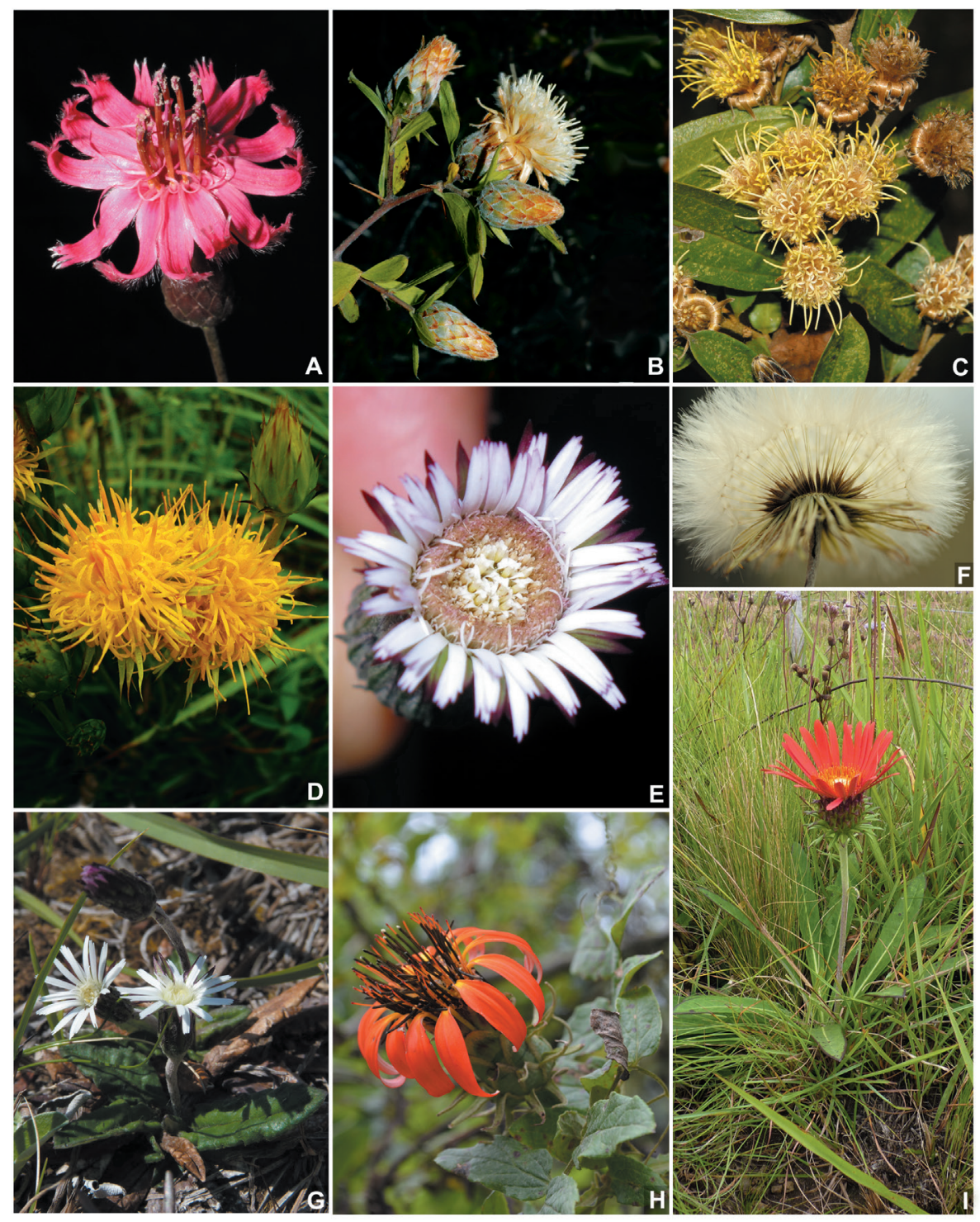

Figura 2. Barnadesieae. A. Barnadesia caryophylla (Vell.) S.F. Blake; B. Dasyphyllum sprengelianum (Gardner) Cabrera; C. Dasyphyllum spinescens (Less.) Cabrera; D. Schlechtendalia luzulifolia Less. Mutisieae. E.

Chaptalia nutans (L.) Polak; F. Chaptalia integerrima (Vell.) Burkart; G. Chaptalia runcinata Kunth. H. Mutisia campanulata Less.; I. Trichocline macrocephala Less. 

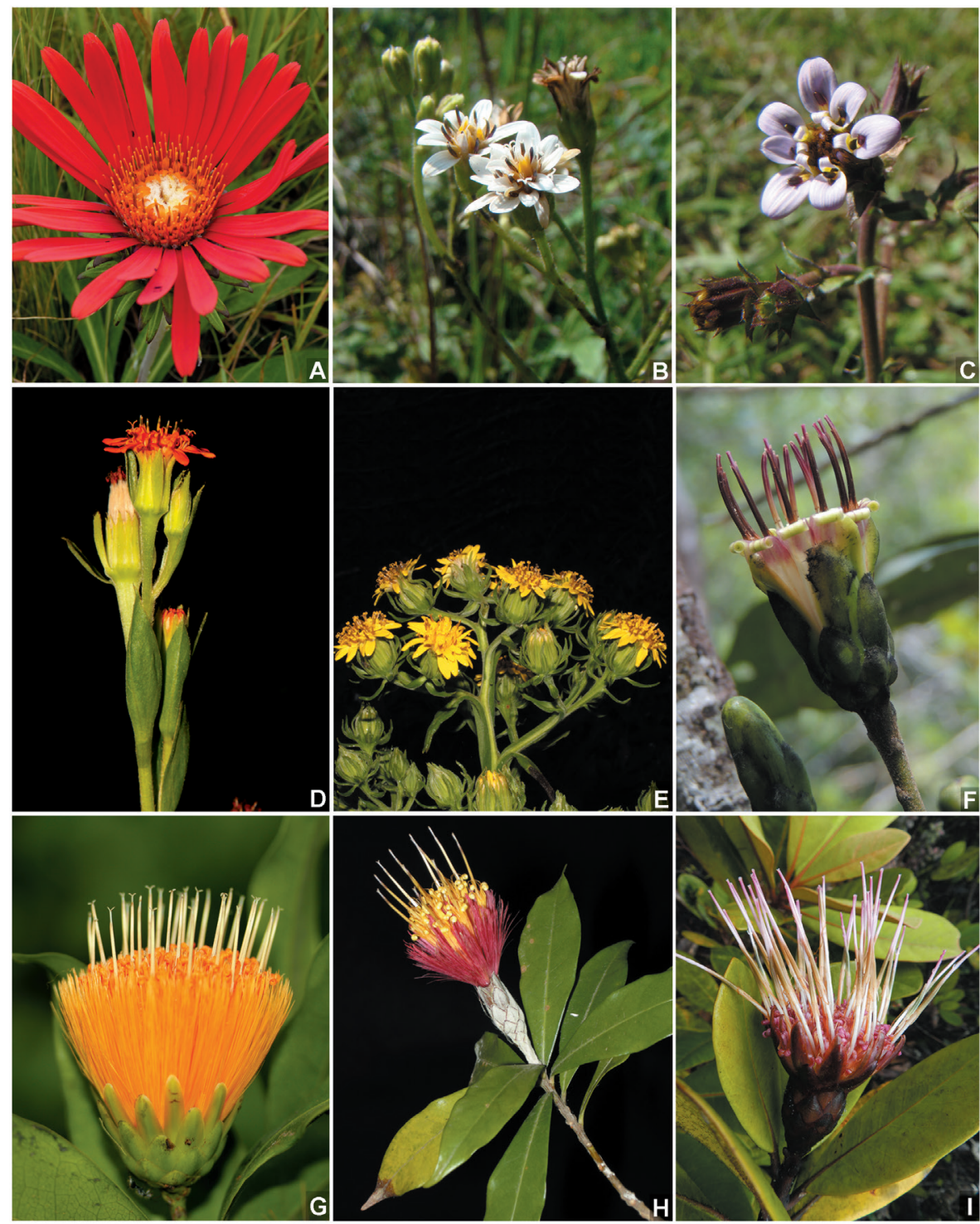

Figura 3. Mutisieae. A. Trichocline macrocephala Less.; Nassauvieae. B. Holocheilus pinnatifidus (Less.) Cabrera; C. Perezia squarrosa subsp. cubaetensis (Less.) Vuilleumemier; D. Trixis lessingii DC.; E. Trixis verbascifolia (Gardner) S.F. Blake; Stifftieae. F. Gongylolepis martiana (Baker) Steyerm. \& Cuatrec.; G. Stifftia chrysantha J.C. Mikan; H. Stifftia fruticosa (Vell.) D.J.N. Hind \& Semir. Wunderlichieae. I. Stenopadus talaumifolius S.F. Blake. 